\title{
Tumor volume is a better predictor of post-operative wound complications compared to tumor size in soft tissue sarcomas of the proximal lower extremity
}

\author{
Michael Ziegele ${ }^{1}$, David M. King ${ }^{1}$ and Manpreet Bedi2 $2^{*}$
}

\begin{abstract}
Background: Wide local excision with or without radiation therapy (RT) and chemotherapy is widely accepted as appropriate management for soft tissue sarcomas (STS) of the extremity. Although survival and local control rates are comparable to amputation, post-operative wound complications (WC) following limb salvage can result in significant morbidity for the patient. Certain risk factors such as location, pre-operative RT, and age have been shown to increase the risk of WCs. Somewhat surprisingly, size has not consistently been shown to impact WC rates. The goal of this study is to assess whether tumor volume, as opposed to the traditional measurement of the largest dimension in one plane, correlates with the development of post-operative WCs.

Methods: Between 2000 and 2013, 81 patients with STS of the proximal lower extremity, buttock and pelvis were retrospectively identified from our prospective database. We reviewed the impact of patient, tumor, and treatment variables on postoperative WC. Predictors for WC were evaluated using the Fisher exact test for univariate analysis and logistic regression for multivariate analysis. Tumor volume was determined using the medical image merge (MIM) ${ }^{\circledR}$ software program (version 6.5.4, MIM Software, Cleveland, $\mathrm{OH}$ ). Tumor size (diameter) was determined the historical way of measuring the widest dimension on the sagittal, coronal, and axial planes from the MRI scan at midplane.

Results: The overall WC rate within 6 months of tumor resection was $32 \%$. WC were more likely to occur with larger tumor volumes $(p=0.015)$, although not with tumor diameters $\geq 10 \mathrm{~cm}(p=0.55)$. Neither volume of subcutaneous fat $(p=0.34)$ or depth of the subcutaneous fat layer $(p=0.82)$ significantly impacted WC rates. Tumor proximity to skin surface also did not significantly impact WC risk $(p=0.73)$.

Conclusions: Increase in tumor volume led to a higher risk of post-operative WCs. Assessing tumor volume may allow clinicians to better counsel patients on their risk of post-operative WCs. Tumor volume, as opposed to size alone, should be considered in future sarcoma outcome studies.
\end{abstract}

\section{Background}

Approximately 12,000 patients in the United States each year are diagnosed with soft tissue sarcomas (STS), representing roughly $1 \%$ of all adult malignancies [1]. In the past, due to concern for high local recurrence rates with local excision, amputation was routinely performed.

\footnotetext{
*Correspondence: mbedi@mcw.edu

${ }^{2}$ Department of Radiation Oncology, Medical College of Wisconsin, 9200

West Wisconsin Ave, Milwaukee, WI 53226, USA

Full list of author information is available at the end of the article
}

However, there has been a transition in the management of STS of the extremity towards limb salvage resection in combination with radiation therapy (RT) with or without chemotherapy. This treatment approach has resulted in excellent local control rates [2, 3].

Despite advances in the treatment of STS, postoperative wound complications (WC) following surgical resection of the tumor remain an important source of morbidity for patients. WC have been reported in $16-56 \%$ of surgical cases $[4,5]$, and can include 
complications such as seromas, hematomas, wound necrosis, wound dehiscence, cellulitis, and abscess formation.

Considerable research has been dedicated towards investigating risk factors for WC follow surgical resection of STS. Risk factors include, but are not limited to, location of disease, tumor size and proximity to skin, and timing of radiation. Tumor location is a strong predictive factor, with tumors located in the lower extremity (LE) experiencing higher rates of WC following surgery [610]. Korah et al. demonstrated that tumor location was the single most important risk factor for $\mathrm{WC}$, and also reports a wound reoperation rate of $29 \%$ for LE tumors vs. $4 \%$ in upper extremity (UE) tumors [7].

Although location of the primary tumor has been consistently shown to impact the development of postoperative WCs, this has not been the case for tumor size. Moreover, most studies that evaluate size as a risk factor take into consideration the maximal dimension of the primary tumor. While the maximal measurement in one dimension gives an idea of tumor size, the overall size, or volume, difference between a $3 \times 10 \mathrm{~cm}$ tumor and a $9 \times 10 \mathrm{~cm}$ tumor is notable. There has been little information on the volume of the tumor and correlation to post-operative WCs.

Similar to tumor size, body mass index (BMI) and the amount of subcutaneous fat has not repeatedly been shown to influence WCs. This lack of consistency perhaps demonstrates that more than one measurement variable effects this outcome.

The objective of this study was to investigate additional variables that might impact post-operative WCs following surgical resection of STS. Specifically, utilizing a combination of volumetric and linear data gathered from preoperative MRIs, we determined if tumor volume and the ratio of subcutaneous (SC) fat, muscle and tumor impacted WC risk. To our knowledge the impact of SC fat on WC rates has never been investigated in STS, although high levels of SC fat have been linked with increased WC rates in other surgical procedures [11-13]. Additionally, the ability of tumor diameter to predict WC risk in comparison to tumor volume has never been investigated.

\section{Methods}

This research was reviewed and approved by the Institutional Review Board (IRB) and all investigators completed training in both human research and patient privacy.

\section{Patient population}

All patients with localized primary STS of the proximal LE, buttock, and pelvis who underwent wide surgical resection, with or without radiation, and/or chemotherapy between 2000 and 2013 were reviewed. Pelvic tumors in this study included sarcomas in the pelvis and buttock that were extra-peritoneal. No retroperitoneal or peritoneal tumors were included in this study. Additional exclusion criteria included metastatic disease on initial presentation, age $<18$ years old, STS of locations other than the proximal LE, buttock, or pelvis, recurrent or non-oncologic resection of sarcomas at first presentation to our sarcoma center, and small subcutaneous tumors. All patients underwent resection. Patients who had radiation (preoperative or post-operative) or no radiation were included in the study. Patients who did not have complete medical records including treatment information and a pathology report, and follow-up of less than 6 months were also excluded. Histopathologic types demonstrating rhabdomyosarcoma, extraosseous primitive neuroectodermal tumor, Kaposi's sarcoma, angiosarcoma, and desmoid fibromatosis were also excluded.

Eighty-one patients were identified in our database who met the inclusion criteria. Patients were staged according to the 2009 American Joint Committee on Cancer (AJCC) system seventh edition.

\section{Treatment}

All patients were discussed at a multidisciplinary tumor board consisting of surgical and musculoskeletal oncologists, medical and radiation oncologists, radiologists and pathologists. Treatment recommendations from this tumor board were presented to the patient.

\section{Radiotherapy and chemotherapy}

Patients included in this study had either preoperative, post-operative or no RT. Those that had preoperative $\mathrm{RT}$ received a median dose of $50 \mathrm{~Gy}$ using $3 \mathrm{D}$-conformal radiation or intensity-modulated radiotherapy (IMRT). Patients who received post-operative $\mathrm{RT}$ received a median dose of $60 \mathrm{~Gy}$.

Chemotherapy was recommended and administered in patients who were typically $<70$ years of age, with large $(>5 \mathrm{~cm})$, deep, and high-grade lesions. Chemotherapy was a doxorubicin-ifosfamide based regimen given for 1-3 cycles based on clinical response and tolerance.

\section{Surgery}

Limb-sparing resection was performed in all patients. Wide surgical resection was performed by fellowship trained musculoskeletal oncologists grossly through normal tissue planes with sacrifice of arteries or veins that were involved by tumor. Preservation of neurovascular structures was performed when possible. The goal of surgery was to achieve negative margins (R0). Vascular or reconstructive plastic surgeons were involved in cases 
that required vascular reconstruction, difficult wound closures and free flap reconstructions.

\section{Data collection}

Pre-operative MRIs were downloaded into the medical image merge (MIM) ${ }^{\circledR}$ software program (version 6.5.4, MIM Software, Cleveland, OH). MRI's were acquired within 1 month prior to limb-sparing resection. Postoperative MRI's were also identified for linear measurements from the incision to the deep fascia. Using axial views, tumors were identified and contoured from proximal to distal tip, generating data on maximal tumor diameter and tumor volume. Volumes of subcutaneous fat and lean mass (including muscle, bone, and blood vessels) were gathered in a similar manner by contouring the structures from the proximal to distal boundaries of the tumor (Fig. 1). Tumor proximity to skin surface was measured from the point of maximal tumor diameter on the axial view to the future incision site determined from the patient's post-operative MRI. Maximal subcutaneous fat layer depth was also measured in this manner, along the length of the tumor and directly adjacent to the future incision site.

Patient data, including age, sex, BMI, diabetic and smoking status, presence of cardiovascular disease, KPS

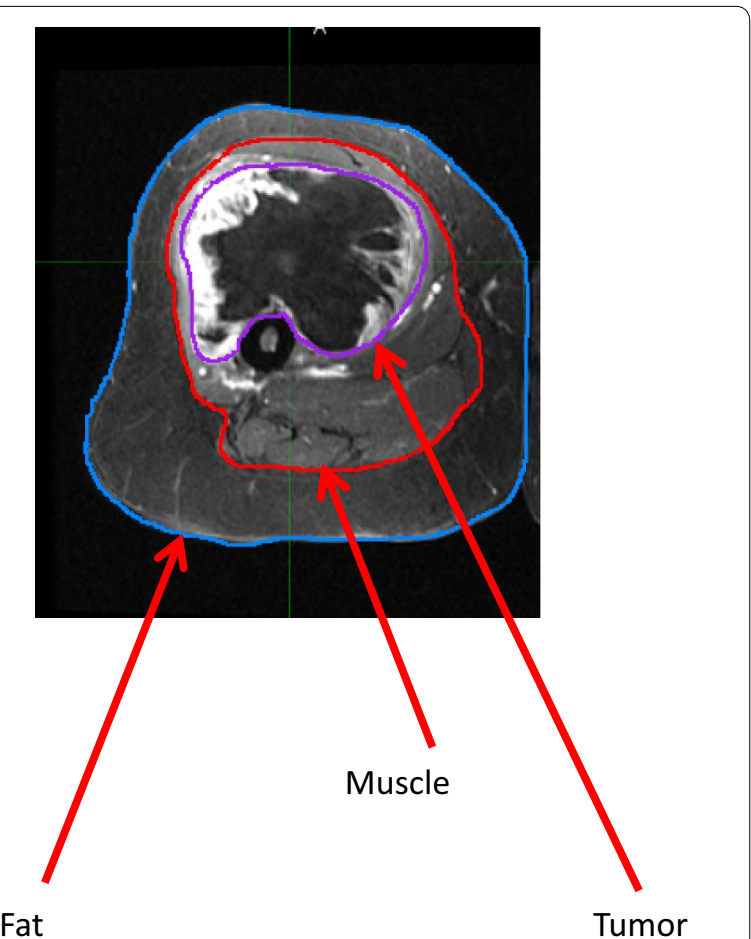

Fig. 1 Forty-eight year old with a high grade myxofibrosarcoma of the proximal thigh. Axial $(A)$, coronal $(B)$ and sagittal $(C)$ views with contours of fat (blue), muscle (red) and tumor (purple) score, tumor histology and stage/grade, use of flap reconstruction, and treatment with chemotherapy were gathered from the existing orthopedic oncology database of STS patients.

\section{Outcomes}

Post-operative WCs were defined as by the Canadian Multicenter Trial and were recorded if they occurred within 6 months following limb-salvage surgery (Table 1). In general, patients who required re-operation, prolonged wound care or antibiotics after resection were considered WC [10].

\section{Statistical analysis}

Statistical software MedCalc (Version 15.6; MedCalc Software bvba, Ostend, Belgium) was used for all data analysis. Clinical, pathologic and treatment characteristics for WC were assessed and summarized in Table 2. Wound outcome was a dichotomous variable. The fisher exact test was used for univariate analysis (UVA). If a variable had a $p$ value of less than 0.25 , then it was used in the multivariate model. A logistic regression analysis was used for multivariate analysis (MVA). For all analysis, type I error was maintained at 0.05 and all tests were two-sided.

A receiver operative characteristic (ROC) curve was constructed and used to examine whether the volumetric data could differentiate between tumors that were predisposed to post-operative WCs versus those that were not predisposed to post-operative WCs.

\section{Results}

Eighty-one patients with stage I-III STS of the LE and buttock underwent treatment at this institution and were eligible for the study. Sixty-nine (85\%) patients had tumors located in the proximal LE, eight (10\%) had tumors in the buttock, and four (5\%) had tumors located in the pelvic region. An overview of patient, tumor, and treatment characteristics can be found in Table 2. Median age at diagnosis was 57 (range: 26-84), and median follow-up was 1.7 years. All 81 patients underwent limbsalvage resection; no patient underwent an amputation at the time of definitive resection.

The overall WC rate within 6 months of tumor resection and as defined by the Canadian Multicenter Trial [10], was $32 \%$ (26 of 81 patients). Of these, ten (38\%) patients developed wound dehiscence and necrotic wounds, ten (38\%) patients developed infection, five (20\%) patients had delayed wound healing, and one (4\%) patient developed a post-operative hematoma. Fiftyfour $(67 \%)$ patients had high grade tumors, four (5\%) intermediate grade, and 23 (28\%) low grade. There was no significant difference in WC rates in patients with 
Table 1 Canadian multicenter wound complication definition

\begin{tabular}{|c|c|}
\hline Wound complication category & Definition \\
\hline Surgical complications & $\begin{array}{l}\text { Secondary operations required for wound treatment } \\
\text { (debridement, secondary closure procedures such as } \\
\text { rotationplasty, free flaps, or skin grafts) } \\
\text { Invasive procedure required for wound care (drainage of } \\
\text { hematoma, seroma, or infected wound collection) } \\
\text { Deep wound packing required at any time (deep pack- } \\
\text { ing defined as packing deep to dermis in an area of } \\
\text { dehisced wound) to an area of the wound measuring } \\
\geq 2 \mathrm{~cm} \text { in length }\end{array}$ \\
\hline Non-surgical complications & $\begin{array}{l}\text { Readmission to hospital for wound care } \\
\text { Prolonged dressing changes, including packing of the } \\
\text { wound for }>6 \text { weeks from wound break down } \\
\text { Failure of epithelialization of skin graft by } 4 \text { weeks after } \\
\text { surgery }\end{array}$ \\
\hline
\end{tabular}

high grade $(29.7 \%)$ vs. low/intermediate grade $(37.0 \%)$ tumors $(\mathrm{p}=0.61)$.

Median BMI of patients in our study was 28.8. WC occurred in 15 patients $(37.5 \%)$ with a BMI $>28.8$, and in eleven patients $(28.2 \%)$ with a BMI $<28.8$; this difference was not significant on UVA $(\mathrm{p}=0.47)$ or MVA $(\mathrm{p}=0.18)$. Similarly, when BMI was analyzed as a continuous variable, it did not significantly impact $\mathrm{WC}$ rates (OR 1.0448, 95 \% CI 0.9746-1.1201, $\mathrm{p}=0.22$ ).

Forty-three patients had a tumor diameter of $\geq 10 \mathrm{~cm}$. The WC rate was $39.5 \%$ with tumors that were $>10 \mathrm{~cm}$ compared to $23.6 \%$ when the primary tumor measured $<10 \mathrm{~cm}$. This failed to reach statistical significance $(p=0.15)$. Increasing tumor volume, however, was associated with higher $\mathrm{WC}$ rates. The median tumor volume of patients in this study was $228.1 \mathrm{~mL}$. WC occurred in $17 / 41$ (41.5\%) patients with a tumor volume $\geq 228.1 \mathrm{~mL}$, and in $9 / 40(22.5 \%)$ patients with a tumor volume $<228.13 \mathrm{~mL} ; \mathrm{p}=0.015)$. Increasing tumor volume was also significant when assessing this measure as a continuous variable $(\mathrm{p}=0.015$, OR $1.0010,95 \%$ CI $1.0001-$ 1.0018). This finding held on MVA ( $\mathrm{p}=0.03$, OR 1.0010, $95 \%$ CI 1.0001-1.0018). A scatter plot depicting tumor size versus volume is located in Fig. 1.

The volume of subcutaneous fat did not significantly impact $\mathrm{WC}$ rates in this study $(\mathrm{p}=0.34$, OR 1.0002 , CI 0.9998-1.0005). In addition, ratios comparing volumes of lean mass to subcutaneous fat ( $\mathrm{p}=0.69$, OR 0.8683 , $95 \%$ CI $0.4306-1.7507$ ) and volumes of subcutaneous fat to tumor ( $\mathrm{p}=0.55$, OR $0.9822,95 \%$ CI $0.9257-1.0421$ ) failed to reveal a significant relationship to WC on logistic regression. Depth of the subcutaneous fat layer at the incision site likewise did not impact WC rates.

Seventy $(86 \%)$ patients underwent preoperative RT, three $(4 \%)$ patients underwent postoperative RT, and eight $(10 \%)$ patients received both pre- and postoperative RT. There were no significant differences in WC rates between these groups. Fifty-six (69 \%) patients received neoadjuvant chemotherapy, which had no significant impact on WC rates upon UVA (35.7 vs. $31.6 \%$, $\mathrm{p}=0.44$ ). No patient included in our study received adjuvant chemotherapy.

Primary closure was utilized for 50 (62\%) patients, while 31 (38\%) patients were selected for a vascularized flap closure with plastic surgery. Use of the flap closure was associated with higher WC rates $(45 \%)$ than primary closure (26\%), a difference which was significant on MVA (OR 3.6969, 95 \% CI 1.2432-10.9938, $\mathrm{p}=0.02$ ). No other variables were significant on UVA or MVA (Table 3 ).

Local control in this cohort was $100 \%$ and the distant metastasis rate was $30.8 \%$. Median survival was not met, but 2-year overall survival was $93.4 \%$. Median and 2-year progression-free survival was 66 months and $65 \%$, respectively. Similarly, median and 2-year distant metastasis-free survival was 66 months and $65 \%$, respectively.

\section{Discussion}

While pre-operative RT combined with wide surgical resection of STS improves disease free survival and has become the standard in limb salvage care at many institutions, post-operative WCs remain a considerable source of morbidity for patients. Several studies have investigated variables that influence post-operative WCs, which include, but are not limited to tumor size and location, proximity to skin surface, radiation field size, and timing of radiation $[4,14-16]$.

Location of the primary tumor has consistently been shown to impact post-operative WCs. Moore et al. reports a $23 \%$ difference in WC rate for proximal LE tumors and proximal UE tumors [6]. Tumors in the adductor compartment of the proximal thigh are particularly prone to $\mathrm{WC}$, a trend likely explained by disruption of the lymphatic network of the LE which occurs during surgery [6]. For this study, we wanted to eliminate the 
Table 2 Clinical, pathologic, and treatment characteristics

\begin{tabular}{|c|c|}
\hline \multicolumn{2}{|l|}{ Age (years) } \\
\hline Mean & 58.2 \\
\hline Median & 57 \\
\hline Range & $26-84$ \\
\hline \multicolumn{2}{|l|}{ Gender } \\
\hline $\mathrm{F}$ & $30(37 \%)$ \\
\hline M & $51(63 \%)$ \\
\hline \multicolumn{2}{|l|}{ Performance status (KPS) } \\
\hline $81-100$ & $71(88 \%)$ \\
\hline$\leq 80$ & $10(12 \%)$ \\
\hline \multicolumn{2}{|l|}{ Cardiovascular disease } \\
\hline No & $74(91 \%)$ \\
\hline Yes & $7(9 \%)$ \\
\hline \multicolumn{2}{|l|}{ Diabetes } \\
\hline No & $72(89 \%)$ \\
\hline Yes & $9(11 \%)$ \\
\hline \multicolumn{2}{|l|}{ Smoking history } \\
\hline No & $57(70 \%)$ \\
\hline Yes & $24(30 \%)$ \\
\hline \multicolumn{2}{|l|}{ Stage } \\
\hline । & $20(25 \%)$ \\
\hline$\|$ & $10(12 \%)$ \\
\hline III & $51(63 \%)$ \\
\hline \multicolumn{2}{|l|}{ Size } \\
\hline$<10 \mathrm{~cm}$ & $38(47 \%)$ \\
\hline$\geq 10 \mathrm{~cm}$ & $43(53 \%)$ \\
\hline \multicolumn{2}{|l|}{ Location } \\
\hline Proximal lower extremity & $69(85 \%)$ \\
\hline Buttock & $8(10 \%)$ \\
\hline Hip/pelvis & $4(5 \%)$ \\
\hline \multicolumn{2}{|l|}{ Grade } \\
\hline Low & $23(28 \%)$ \\
\hline Intermediate & $4(5 \%)$ \\
\hline High & $54(67 \%)$ \\
\hline \multicolumn{2}{|l|}{ Histology } \\
\hline Undifferentiated & $10(12 \%)$ \\
\hline Liposarcoma/leiomyosarcoma & $31(38 \%)$ \\
\hline Myxofibrosarcoma & $11(14 \%)$ \\
\hline Synovial & $4(5 \%)$ \\
\hline Spindle cell & $13(16 \%)$ \\
\hline Other & $12(15 \%)$ \\
\hline \multicolumn{2}{|l|}{ Neoadjuvant chemotherapy } \\
\hline No & $25(31 \%)$ \\
\hline Yes & $56(69 \%)$ \\
\hline \multicolumn{2}{|l|}{ Timing of RT } \\
\hline No RT & $8(10 \%)$ \\
\hline Preoperative RT & $70(86 \%)$ \\
\hline Post-operative RT & $3(4 \%)$ \\
\hline \multicolumn{2}{|l|}{ Flap reconstruction } \\
\hline No & $50(62 \%)$ \\
\hline Yes & $31(38 \%)$ \\
\hline
\end{tabular}

Table 3 UVA of WC variables

\begin{tabular}{ll}
\hline Variable & p value \\
\hline BMI $(>28 /<28)$ & 0.474 \\
Neoadjuvant chemo $(\mathrm{Y} / \mathrm{N})$ & 0.440 \\
Cardiovascular disease $(\mathrm{Y} / \mathrm{N})$ & 0.675 \\
Diabetes $(\mathrm{Y} / \mathrm{N})$ & 0.458 \\
Smoking $(\mathrm{Y} / \mathrm{N})$ & 0.798 \\
Grade $($ high grade/non-high grade) & 0.615 \\
KPS score $(>80 / \leq 80)$ & 0.278 \\
Sex $(\mathrm{M} / \mathrm{F})$ & 0.474 \\
Tumor size $(\geq 10 \mathrm{~cm} /<10 \mathrm{~cm})$ & 0.156 \\
Flap closure $(\mathrm{Y} / \mathrm{N})$ & 0.055 \\
\hline
\end{tabular}

confounding influence of tumor location on WC risk. Therefore, our cohort only included patients with tumors in the proximal LE, buttock, or pelvic area.

Tumor size is a strong predictor of WC risk, a relationship which is demonstrated by multiple studies $[4,6,7$, $10,17]$. Tumors greater than $10 \mathrm{~cm}[4,6,10], 8 \mathrm{~cm}$ [7], and even $5 \mathrm{~cm}$ in diameter [18] have all been shown to be associated with higher WC risk. A probable explanation for the impact of tumor size on WC rates is that larger tumors generate a greater dead-space in the soft tissue following resection, predisposing the patient to seromas, hematomas, and infection. Our study did not demonstrate that tumors greater than $10 \mathrm{~cm}$ in diameter were associated with a statistically significant higher risk of WCs. We did however find a statistically significant relationship between tumor volume and WC rate, establishing that increasing tumor volume predicts a greater risk of postoperative WC. This finding first corroborates prior research on the importance of tumor size as a risk factor for postoperative WC. More notably however, it also suggests that tumor volume, rather than tumor diameter or cross-sectional area, is a more powerful predictor of postoperative WC risk. Moreover, as conveyed in Fig. 2,

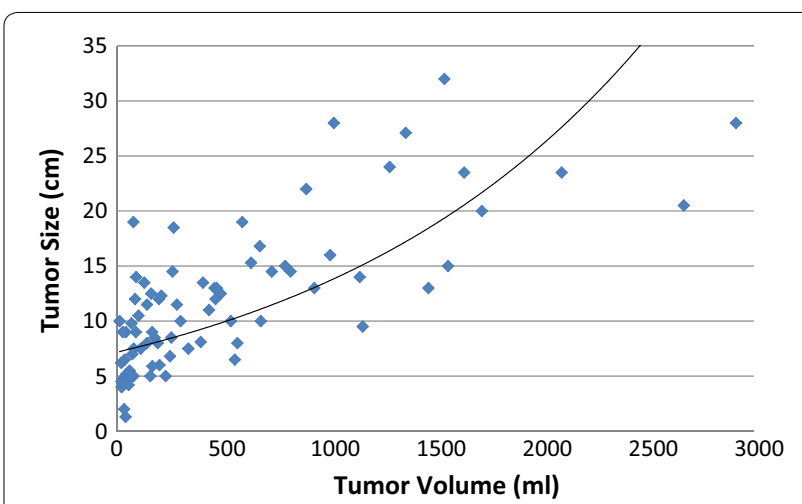

Fig. 2 Tumor size vs. tumor volume scatter plot 
a

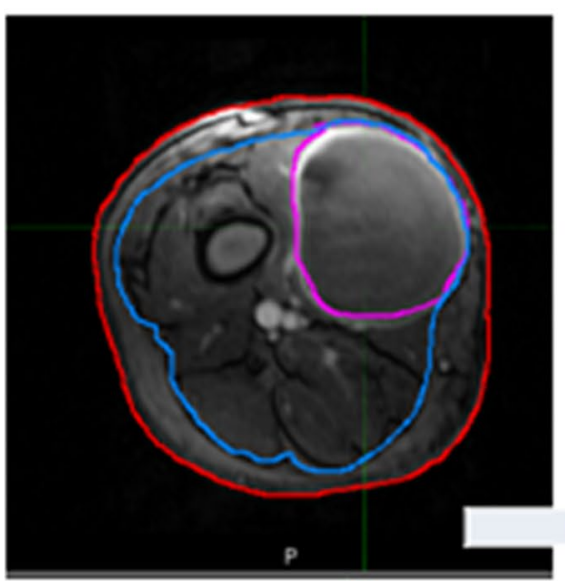

Patient A: Axialview.

Tumor size: $11.5 \mathrm{~cm}$

Tumor volume: $281.24 \mathrm{~mL}$

b

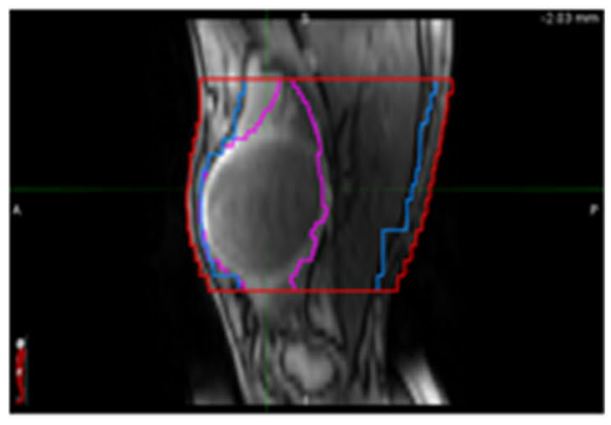

Patient A: Sagittalview.

Tumor size: $11.5 \mathrm{~cm}$

Tumor volume: $281.24 \mathrm{~mL}$

C

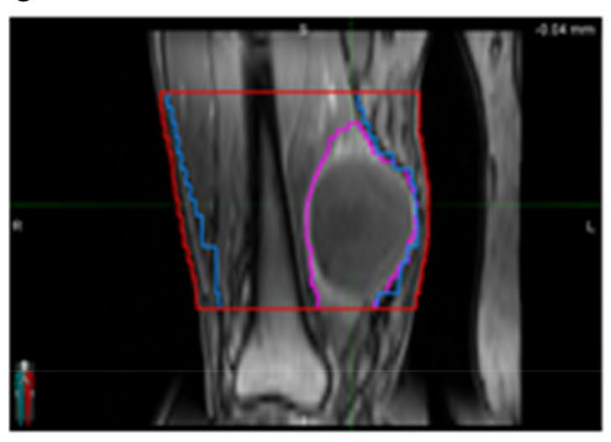

Patient A: Coronal view.

Tumor size: $11.5 \mathrm{~cm}$

Tumorvolume: $281.24 \mathrm{~mL}$

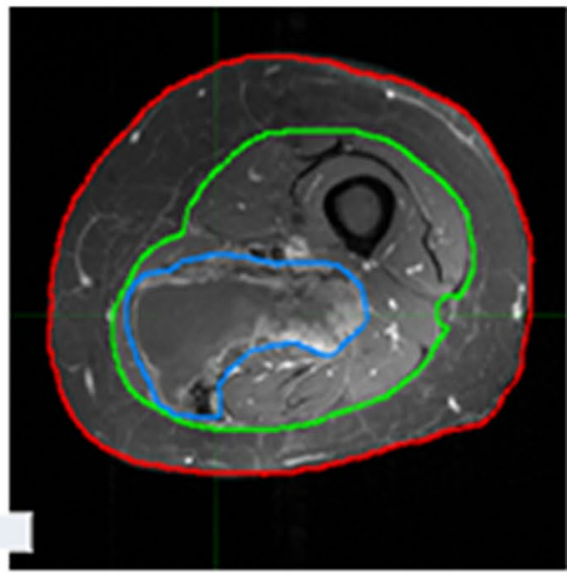

Patient B: Axial View

Tumor size: $11 \mathrm{~cm}$

Tumor volume: $432.33 \mathrm{~mL}$

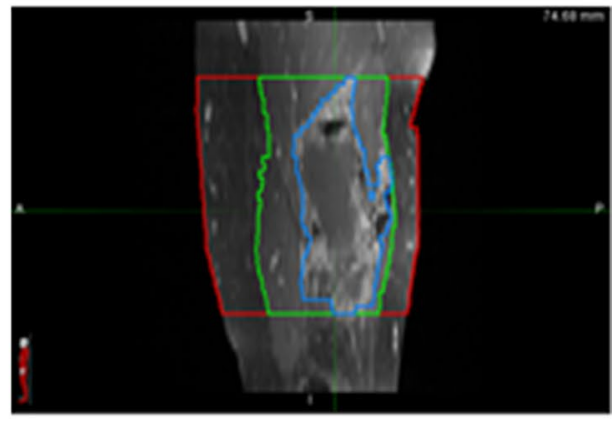

Patient B: Sagittal View

Tumor size: $11 \mathrm{~cm}$

Tumor volume: $432.33 \mathrm{~mL}$

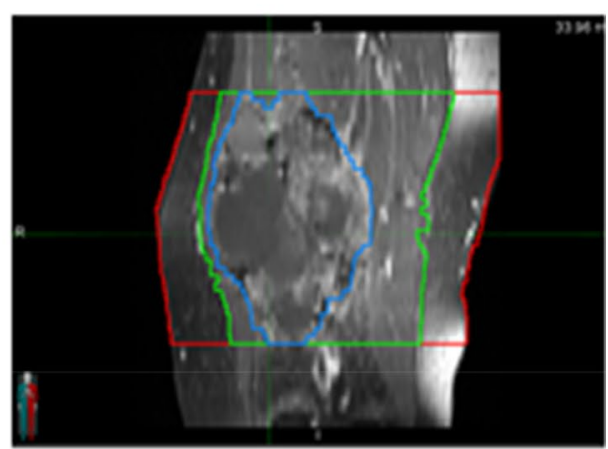

Patient B: CoronalView

Tumor size: $11 \mathrm{~cm}$

Tumor volume: $432.33 \mathrm{~mL}$

Fig. 3 a Patient A and B's Tumor size and corresponding volume on axial view. b Patient A and B's tumor size and corresponding volume on sagittal view. c Patient A and B's tumor size and corresponding volume on coronal view 
there seems to be little relationship between size and volume, most likely because STS are often not spherical, but have an irregular shape. Thus, as mentioned above, maximal dimension may only provide one component influencing WC, and it is truly the volume that impacts this outcome. By measuring a 3-dimensional tumor in only one plane it is easy to over or under estimate true tumor burden, thereby misjudging the soft-tissue defect which will be left post-resection along with the associated WC risk (Fig. 3a-c). Work by Geller et al. has previously demonstrated that tumor volume is associated with WC risk [5]. In this study however, tumor volume was measured from final gross pathology specimens and was also not compared to tumor diameter or cross sectional area. To our knowledge, our study is the first to assess if tumor volumes contoured from preoperative MRIs predict postoperative WC risk. It also for the first time demonstrates that volumetric measurements may be more representative of tumor size than measuring tumor diameter, a finding which has implications for predicting WC risk, as well as potentially other treatment outcomes, preoperatively.

With the expanding obesity epidemic in the United States, the impact of subcutaneous fat on WC risk is a crucial area of investigation in STS. BMI has failed to demonstrate a significant association with WCs in prior studies [6], as well as our own. However, BMI fails to take into account factors such as gender differences in adipose tissue distribution and also levels of lean muscle mass which may weaken any association with WC risk. Levels of subcutaneous fat tissue surrounding the incision site has yet to be investigated in STS, although it has been demonstrated to impact WC rates in other arenas of surgery. In one study of cervical spine fusions, patients with subcutaneous fat layer depths of $>40 \mathrm{~mm}$ were at significantly higher risk of surgical site infection (18.2 \%) than patients with thinner layers of $<20 \mathrm{~mm}(5.2 \%)$ and $<10 \mathrm{~mm}(2.3 \%)$ [17]. Similar results have been published in gynecologic and general surgery, indicating that the thickness of SC fat surrounding the incision site impacts WC risk [11-13, 19, 20]. Increased SC fat thickness necessitates a longer surgical incision, as well as increased retraction which may lead to tissue necrosis at the operative site. A thicker subcutaneous layer also increases wound tension at closure, placing the patient at increased risk for wound dehiscence and also reducing tissue microperfusion and oxygen availability to the wound [21]. In contrast to the aforementioned research, our study did not demonstrate a significant relationship between WC risk and either subcutaneous fat volume or depth of the adipose layer adjacent to the incision. One limitation to our study which may have impacted results is that a nine of the preoperative MRIs had small sections of peripheral tissue cut off, not allowing us to fully contour fat and muscle layers. Additionally, our measurement of subcutaneous fat volume included adipose tissue from the entire circumference of the leg, not just surrounding the incision site. An avenue for future research may be measurement of the SC fat volume surrounding only the leg compartment specific to the tumors location.

Reconstruction of surgical wounds with vascularized flaps is utilized as an alternative to primary closure following resection of STS. It is intended to lower WC risk through minimizing residual dead space and also substituting previously irradiated soft tissues with healthy and well-vascularized tissue from a donor site. The literature returns mixed results on the impact of plastic reconstruction on WC risk; some studies conclude that it lowers risk [22], others find that it increases it [4], while yet others demonstrate no impact [6]. Analysis of our patient cohort indicates that reconstruction with vascularized flaps was a statistically significant risk factor for WC. It should be noted however that there is likely a strong element of selection bias in this finding. Patients selected for immediate flap reconstruction at our institution were often those felt to be at higher risk for postoperative WC. These included patients with greater tumor volumes, vascular involvement of their tumor, and host comorbidities which may have increased their risk for WCs.

The association between preoperative RT and increased WC risk has been well established. O'Sullivan et al. reported an $18 \%$ increase in WC rate with preoperative $\mathrm{RT}$ in comparison to postoperative RT, a finding which has been replicated by additional studies $[6,23]$. Timing of RT was not a significant risk factor for WC in our study; however this is not surprising as the vast majority of our patients underwent preoperative RT. Similarly, the administration of neoadjuvant chemotherapy did not predispose patients to $\mathrm{WC}$ in our study. This is a finding which is consistent with other published work.

Baldini et al. describes that tumor proximity to skin surface impacts WC risk, reporting that tumors located $<3 \mathrm{~mm}$ from the skin surface increase risk for WC (OR 3.9) [4]. This finding however has not been replicated in additional research [6], and is also not shown in our findings. Timing of radiotherapy in our study may be a factor in this negative result. Baldini et al. suggests that preoperative RT of superficial tumors delivers an unavoidably high radiation dose to the surgical flaps used in wound closure, increasing the risk for WC. While the majority of patients in our study received preoperative RT (86 \%), some did undergo postoperative RT or no RT at all, which may have impacted results. Another possibility is that our small sample size limited our ability to find a significant relationship.

One weakness of our study was our small sample size. STS are exceedingly rare cancers, and by restricting our 
study population to only patients with tumors in the proximal LE, buttock, or pelvis, we limited our sample size. This could potentially explain why some of our results did not reach the level of statistical significance. For instance, prior research has demonstrated diabetes to be powerful risk factor for $\mathrm{WC}$ following resection of STS $[4,6]$. In our study there were large differences in WC risk for patients with diabetes (44.4 vs. $30.6 \%)$. This difference was not significant however, which may be due to our analysis being underpowered. Additional limitations to our study include the retrospective nature of the study and the inherent biases which come with this design, as well as the limited field of view on nine of the preoperative MRIs which limited our ability to accurately contour structures. Another limitation of the study is the potential error in the volume measurements. Contouring structures on MRI scans is a very operator dependent process, and results may vary from person to person based on contouring technique. We attempted to limit the potential impact of this by having all measurements acquired by a single researcher. Although all data was generated by a single researcher in our study, the intra and inter-observer variability associated with the volume measurement technique is unknown and attempts to replicate this research in the future may be prone to this bias.

\section{Conclusions}

In this study, it was tumor volume, more than size that impacted the development of post-operative WCs. Our study demonstrates that gathering data on tumor volume, rather than diameter, may be a more accurate means of predicting WC risk. Tumor volume measurements could allow clinicians to more accurately counsel patients regarding their risk of WCs and also arrange for more aggressive follow-up and prophylactic regimens to combat the risk of WC. Further investigations on the relationship between volumetric parameters and treatment outcomes are warranted.

\section{Abbreviations \\ BMI: body mass index; Cl: confidence interval; Gy: gray; MIM: medical image merge; MVA: multivariate analysis; STS: soft tissue sarcomas; UVA: univariate analysis; WC: wound complication.}

\section{Authors' contributions}

MZ: conducted a literature search, analysis and drafted the manuscript. MB: assisted with the literature search, formulated project design, performed data analysis, and assisted in manuscript construction and editing. DK: formulated project design and supervised the study. DK also assisted in manuscript construction and editing. All authors read and approved the final manuscript.

\section{Author details}

${ }^{1}$ Department of Orthopaedic Surgery, Medical College of Wisconsin, 9200 West Wisconsin Ave, Milwaukee, WI 53226, USA. ${ }^{2}$ Department of Radiation
Oncology, Medical College of Wisconsin, 9200 West Wisconsin Ave, Milwaukee, WI 53226, USA.

\section{Competing interests}

The authors declare that they have no competing interests.

Funding source

There were no funding sources available for this project.

Received: 14 September 2015 Accepted: 4 February 2016

Published online: 22 February 2016

\section{References}

1. Jemal A, Murray T, Ward E, Samuels A, Tiwari RC, Ghafoor A, Feuer EJ, Thun MJ. Cancer statistics, 2005. CA Cancer J Clin. 2005;55(1):10-30 (Erratum in: CA Cancer J Clin. 2005 Jul-Aug;55(4):259. PubMed PMID: 15661684).

2. Suit HD, Spiro I. Role of radiation in the management of adult patients with sarcoma of soft tissue. Semin Surg Oncol. 1994;10(5):347-56.

3. Yang JC, Chang AE, Baker AR, Sindelar WF, Danforth DN, Topalian SL, DeLaney T, Glatstein E, Steinberg SM, Merino MJ, Rosenberg SA. Randomized prospective study of the benefit of adjuvant radiation therapy in the treatment of soft tissue sarcomas of the extremity. J Clin Oncol. 1998;16(1):197-203.

4. Baldini EH, Lapidus MR, Wang Q, Manola J, Orgill DP, Pomahac B, Marcus KJ, Bertagnolli MM, Devlin PM, George S, Abraham J, Ferrone ML, Ready JE, Raut CP. Predictors for major wound complications following preoperative radiotherapy and surgery for soft-tissue sarcoma of the extremities and trunk: importance of tumor proximity to skin surface. Ann Surg Oncol. 2013;20(5):1494-9. doi:10.1245/s10434-012-2797-1 (Epub 2012 Dec 15).

5. Geller DS, Hornicek FJ, Mankin HJ, Raskin KA. Soft tissue sarcoma resection volume associated with wound-healing complications. Clin Orthop Relat Res. 2007;459:182-5.

6. Moore J, Isler M, Barry J, Mottard S. Major wound complication risk factors following soft tissue sarcoma resection. Eur J Surg Oncol. 2014;40(12):1671-6. doi:10.1016/j.ejso.2014.10.045.

7. Korah MP, Deyrup AT, Monson DK, Oskouei SV, Weiss SW, Landry J, Godette KD. Anatomic tumor location influences the success of contemporary limb-sparing surgery and radiation among adults with soft tissue sarcomas of the extremities. Int J Radiat Oncol Biol Phys. 2012;82(2):9339. doi:10.1016/j.jirobp.2010.11.020 (Epub 2011 Feb 6).

8. Prendergast B, Fiveash JB, Gibbs CP, Scarborough MT, Indelicato DJ. Radiotherapy for soft tissue sarcoma of the proximal lower extremity. Sarcoma. 2010;2010:829498. doi:10.1155/2010/829498 (Epub 2010 Oct 14).

9. Schwartz A, Rebecca A, Smith A, Casey W, Ashman J, Gunderson L, Curtis K, Chang YH, Beauchamp C. Risk factors for significant wound complications following wide resection of extremity soft tissue sarcomas. Clin Orthop Relat Res. 2013;471(11):3612-7. doi:10.1007/s11999-013-3130-4 (Epub 2013 Jun 28).

10. O'Sullivan B, Davis AM, Turcotte R, Bell R, Catton C, Chabot P, Wunder J, Kandel R, Goddard K, Sadura A, Pater J, Zee B. Preoperative versus postoperative radiotherapy in soft-tissue sarcoma of the limbs: a randomised trial. Lancet. 2002;359(9325):2235-41.

11. Tsukada K, Miyazaki T, Kato H, Masuda N, Fukuchi M, Fukai Y, Nakajima M, Ishizaki M, Motegi M, Mogi A, Sohda M, Moteki T, Sekine T, Kuwano H. Body fat accumulation and postoperative complications after abdominal surgery. Am Surg. 2004;70(4):347-51.

12. Yamada T, Okabayashi K, Hasegawa H, Tsuruta M, Abe Y, Ishida T, Matsui S, Kitagawa Y. Age, preoperative subcutaneous fat area, and open laparotomy are risk factors for incisional hernia following colorectal cancer surgery. Ann Surg Oncol. 2015;23(Suppl 2):236-41.

13. Soper DE, Bump RC, Hurt WG. Wound infection after abdominal hysterectomy: effect of the depth of subcutaneous tissue. Am J Obstet Gynecol. 1995;173(2):465-9 (discussion 469-71). 
14. Cannon CP, Ballo MT, Zagars GK, Mirza AN, Lin PP, Lewis VO, et al. Complications of combined modality treatment of primary lower extremity soft tissue sarcomas. Cancer. 2006;107:2455-61.

15. Arbeit JM, Hilaris BS, Brennan MF. Wound complications in the multimodality treatment of extremity and superficial truncal sarcomas. J Clin Oncol. 1987;5:480-8.

16. Kunisada T, Ngan SY, Powell G, Choong PFM. Wound complications following pre-operative radiotherapy for soft tissue sarcoma. EJSO. 2002;28:75-9.

17. Mehta Al, Babu R, Sharma R, Karikari IO, Grunch BH, Owens TR, Agarwal VJ, Sampson JH, Lad SP, Friedman AH, Kuchibhatla M, Bagley CA, Gottfried ON. Thickness of subcutaneous fat as a risk factor for infection in cervical spine fusion surgery. J Bone Joint Surg Am. 2013;95(4):323-8. doi:10.2106/JBJS.L.00225.

18. Cannon CP, Ballo MT, Zagars GK, Mirza AN, Lin PP, Lewis VO, Yasko AW, Benjamin RS, Pisters PW. Complications of combined modality treatment of primary lower extremity soft-tissue sarcomas. Cancer. 2006;107(10):2455-61

19. Fujii T, Tsutsumi S, Matsumoto A, Fukasawa T, Tabe Y, Yajima R, Asao T, Kuwano $H$. Thickness of subcutaneous fat as a strong risk factor for wound infections in elective colorectal surgery: impact of prediction using preoperative CT. Dig Surg. 2010;27(4):331-5. doi:10.1159/000297521 (Epub 2010 Aug 3).

20. Sugisawa N, Tokunaga M, Tanizawa Y, Bando E, Kawamura T, Terashima M. Intra-abdominal infectious complications following gastrectomy in patients with excessive visceral fat. Gastric Cancer. 2012;15:206-12.

21. Guo S, Dipietro LA. Factors affecting wound healing. J Dent Res. 2010;89(3):219-29. doi:10.1177/0022034509359125 (Epub 2010 Feb 5. Review).

22. Griffin AM, Dickie Cl, Catton CN, Chung PW, Ferguson PC, Wunder JS, O'Sullivan B. The influence of time interval between preoperative radiation and surgical resection on the development of wound healing complications in extremity soft tissue sarcoma. Ann Surg Oncol. 2015;22:2824-30

23. Peat BG, Bell RS, Davis A, O'Sullivan B, Mahoney J, Manktelow RT, Bowen V, Catton C, Fornasier VL, Langer F. Wound-healing complications after soft-tissue sarcoma surgery. Plast Reconstr Surg. 1994;93(5):980-7.
Submit your next manuscript to BioMed Central and we will help you at every step:

- We accept pre-submission inquiries

- Our selector tool helps you to find the most relevant journal

- We provide round the clock customer support

- Convenient online submission

- Thorough peer review

- Inclusion in PubMed and all major indexing services

- Maximum visibility for your research

Submit your manuscript at www.biomedcentral.com/submit
( Biomed Central 